\title{
Bed-Shear Velocity Measurement in Curved Open Channel
}

\author{
Sumiadi $^{1}$, B.A. Kironoto ${ }^{2}$, Djoko Legono ${ }^{2}$ Istiarto $^{2}$ \\ ${ }^{1}$ Water Resources Engineering Department, Universitas Brawijaya, Malang, 65145, \\ Indonesia \\ ${ }^{2}$ Civil and Environmental Engineering Department,Universitas Gadjah Mada, \\ Yogyakarta, 55281, Indonesia \\ sumiadi_73@ub.ac.id
}

Received 12-01-2021; accepted 05-03-2021

\begin{abstract}
Generally, the condition of the rivers in Indonesia are alluvial rivers which had meanders, where the change in the river bed topography often occur. One of the parameters associated with changes in the river bed topography is bed-shear velocity, or Reynolds stress. The bed-shear velocity can be calculated by the Reynolds stress distribution method and the Clauser method which commonly used in straight channels. In fact, on natural channel there is a curve and even a meandering channel. With more complex flow conditions, the use of the Clauser method in curved channels can be questioned, is it still accurate or not. In this paper, both methods will be discussed by comparing the measurement data in the laboratory using $180^{\circ}$ curved channel with flat bed. The results of data analysis show that the use of these two methods in curved channels produces an average difference of around $19.81 \%$, where the Clauser method gives greater results and better tendencies. Apart from the differences in the results given, it can be said that the Clauser method as well as the Reynolds stress distribution method can still be used to calculate the bed-shear velocity in the curved channel.
\end{abstract}

Keywords: bed-shear velocity, clauser method, curved open channel, reynolds shear stress

\section{Introduction}

Generally, river conditions in Indonesia are meandering and alluvial rivers where the bed material in the form of sand, gravel or clay is easily transported by the flow. Flows in natural rivers and channels are often unsteady. Field studies show that, during the passage of a flood, the bed-load movement is different from those in steady flow[8]. With these conditions, efforts to control the destructive power of the river become a difficult challenge. One aspect that needs attention is the change in the riverbed due to degradation and aggression. One of the parameters associated with the process of channel bed profile changing is the shear velocity parameter, $u_{*}$, or shear stress on the bed, $\tau_{0}$. Shear velocity is determined using velocity profile data, particularly those measured in the inner layer. In loose gravel bed flows, a roughness layer develops just above the bed, thus affecting the lower end of the inner layer velocity profile [6][5]. Under certain conditions, it may be difficult to obtain reliable velocity profile data,

Cite this as: Sumiadi, Kironoto, B.A., Legono, D., \& Istiarto. (2021). Bed-Shear Velocity Measurement in Curved Open Channel. Civil and Environmental Science Journal (Civense), 4(1), 84-92. doi:

https://doi.org/10.21776/ub.civense.2021.00401.9 
particularly in the field. In that case, shear velocity must be estimated from single point measurements [2]. In alluvial rivers that are relatively straight, the effect of flow on the bed shear stress or velocity will be different when compared to the effect of flow on a curve. When the flow enters the curve, there is an increase in secondary flow and triggers an increase in the bed-shear velocity or bed-shear stress. The increase in bed shear velocity results in scouring, especially on the outer bank and settling on the inner bank.

\section{Material and Methods}

\subsection{Methods}

To determine the bed shear velocity, $u *$, in uniform flow, there are several methods that can be used, namely [1]:

1. Energy gradient method

2. Clauser method

3. Reynolds stress distribution method.

From the three methods mentioned above, in this paper only the last two methods will be discussed, namely the Clauser method, which uses tangential velocity measurement data and the second method using Reynolds stress measurement data. While the first method is rather difficult to use, because it is not easy to determine the energy gradient on the curved channel.

\subsubsection{Clauser Method}

At the Clauser method, the bed-shear velocity is obtained based on the tangential velocity profile. With the assumption that the tangential velocity distribution in the inner region follows the logarithmic equation formulated as :

$$
\frac{v_{\theta}}{u_{*}}=\frac{1}{\kappa} \ln \left(\frac{z}{k s}\right)+B r
$$

If the left side and the right side is multiplied by the bed-shear velocity, $u *$ then equation 1 becomes:

$$
v_{\theta}=\frac{u_{*}}{\kappa} \ln \left(\frac{z}{k s}\right)+B r \cdot u_{*}
$$

$v_{\theta}$ is tangential velocity $(\mathrm{m} / \mathrm{s}), u_{*}$ is bed-shear velocity $(\mathrm{m} / \mathrm{s}), z$ : distance from bed-surface $(\mathrm{m}), k_{\mathrm{s}}:$ bed roughness (m), $\kappa$ : von Karman's constant, Br: constant of integration.

Based on equation 2, it is known that the tangential velocity vertical distribution $v_{\theta}$ to $\ln \left(\frac{z}{k s}\right)$ is linear, with a gradient of $\frac{u_{*}}{\kappa}$.

\subsubsection{Reynolds Stress Distribution Method}

In turbulent flow, instantaneous velocity can be separated into two components, namely the average velocity towards time (time average velocity) and velocity fluctuations as illustrated in Figure 1 below.

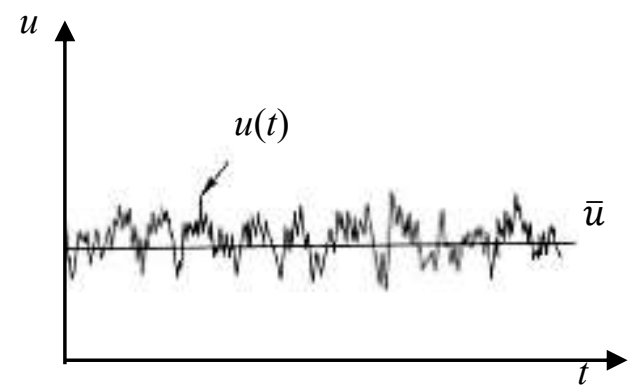

Figure 1. Averaging velocity towards time. 
So that it can be written in the form :

$$
u=\bar{u}+u^{\prime}
$$

where:

$u:$ longitudinal velocity $(\mathrm{m} / \mathrm{s})$

$\bar{u}:$ average velocity $(\mathrm{m} / \mathrm{s})$

$u^{\prime}$ : velocity fluctuations, can be positive or negative $(\mathrm{m} / \mathrm{s})$

Referring to equation 3, then for 3D flow in a curved channel, which consists of tangential, radial and vertical direction velocity components, it can be written as :

$$
v_{\theta}=\overline{v_{\theta}}+v_{\theta}^{\prime} \quad v_{r}=\overline{v_{r}}+v_{r}^{\prime} \quad v_{z}=\overline{v_{z}}+v_{z}^{\prime}
$$

with $v_{\theta}, v_{r}, v_{z}$ are the component of instantaneous velocity, $\overline{v_{\theta}}, \overline{v_{r}}, \overline{v_{z}}$ average velocity component and $v_{\theta}^{\prime}, v_{r}^{\prime}, v_{z}^{\prime}$ are the velocity fluctuation component, respectively in the tangential direction, $\theta$, radial direction, $r$, and vertical direction, $z$.

From Equation 4, then the value of velocity fluctuations $v_{\theta}^{\prime}, v_{r}^{\prime}, v_{z}^{\prime}$ can be stated as:

$$
v_{\theta}^{\prime}=v_{\theta}-\overline{v_{\theta}} \quad v_{r}^{\prime}=v_{r}-\overline{v_{r}} \quad v_{z}^{\prime}=v_{z}-\overline{v_{z}}
$$

Using equation 5 , the magnitude of instantaneous velocity fluctuations can be calculated. While the shear stress in turbulent flow

The shear stress acting on the plane $i$ of the direction $j$ is formulated as:

$$
\tau_{i j}=\rho v\left(\frac{\partial u_{i}}{\partial x_{j}}+\frac{\partial u_{j}}{\partial x_{i}}\right)-\rho \overline{u_{i}^{\prime} u_{j}^{\prime}}
$$

The first term on the right shows the stress caused by the viscosity of water, $(v)$, while the last term shows the effect of velocity fluctuations and is known as the Reynolds stress.

In turbulent flow, the stress caused by the influence of velocity fluctuations (turbulence) is far greater than the stress due to water viscosity. So that the shear stress due to viscosity of water can be ignored. Then equation (6) becomes:

$$
\tau_{i j}=-\rho \overline{u_{i}^{\prime} u_{j}^{\prime}}
$$

For flow in the curved channel, using cylindrical coordinates $(\theta, r, z)$ then for the $\mathrm{z}$ field, there are 3 shear stresses, i.e.:

$$
\begin{aligned}
\tau_{z z} & =-\rho \overline{v_{z}^{\prime} v_{z}^{\prime}} \\
\tau_{z r} & =-\rho \overline{v_{z}^{\prime} v_{r}^{\prime}} \\
\tau_{z \theta} & =-\rho \overline{v_{z}^{\prime} v_{\theta}^{\prime}}
\end{aligned}
$$

where $\tau_{z z}$ is a normal component of shear stress or often referred to as normal stress, while $\tau_{z r}$ and $\tau_{z \theta}$ respectively are components of shear stress in radial and tangential directions or often referred to as Reynolds stresses. Furthermore, what is discussed in this paper is Reynolds stress in the tangential direction, $\tau_{z \theta}$.

Referring to equation 10 , the bed shear stress, $\tau_{\mathrm{o}}$ (tangential direction) can be obtained from measurement data of Reynolds stress distribution in the tangential direction, $\tau_{z \theta}$, for the value of $z=0$, namely $\tau_{z} \theta_{z=0} \approx \tau_{0}$ By extrapolating (or regression) measurement data for tangential Reynolds stress distribution, $\tau_{z \theta}$, at $z=0$, namely: 


$$
\tau_{\mathrm{o}}=\rho u_{*}^{2}=\tau_{z \theta, z=0}=-\left.\rho \overline{v_{z}^{\prime} v_{\theta}^{\prime}}\right|_{z=0}
$$

or:

$$
\frac{\tau_{\mathrm{o}}}{\rho}=u_{*}^{2}=-\left.\overline{v_{z}^{\prime} v_{\theta}^{\prime}}\right|_{z=0}
$$

Based on equation 12, then the bed-shear velocity can be derived.

\subsection{Material}

\subsubsection{Experiments}

This research was conducted at the Hydraulic Laboratory, Department of Civil and Environmental Engineering, Universitas Gadjah Mada using $180^{\circ}$ curved channel with flat bed. Three-dimensional velocity measurements include tangential velocity $\left(v_{\theta}\right)$, radial velocity $\left(v_{r}\right)$ and vertical velocity $\left(v_{z}\right)$. Before entering the curved channel, flow through the approach channel (approach flow). In the upstream of the approach flow also fitted with head tank - to ensure steady/permanent flow conditions - and Thompson type discharge meter.

Furthermore, the flow parameters in the approach flow in detailed are shown in Table 1 below.

Table 1. Flow parameter in approach flow.

\begin{tabular}{ccccccccccc}
\hline $\begin{array}{c}Q \\
(1 / \mathrm{s})\end{array}$ & $\begin{array}{c}B \\
(\mathrm{~cm})\end{array}$ & $\begin{array}{c}h \\
(\mathrm{~cm})\end{array}$ & $\begin{array}{c}\boldsymbol{R}_{\boldsymbol{h}} \\
(\mathrm{cm})\end{array}$ & $\begin{array}{c}\boldsymbol{d}_{\mathbf{5 0}} \\
(\mathrm{cm})\end{array}$ & $\begin{array}{c}S \\
(\% / \mathrm{oo})\end{array}$ & $\begin{array}{c}U \\
(\mathrm{~cm})\end{array}$ & $\begin{array}{c}C \\
\left(\mathrm{~m}^{1 / 2} / \mathrm{s}\right)\end{array}$ & $\begin{array}{c}R e \\
\left(10^{3}\right)\end{array}$ & $F r$ & $B / h$ \\
\hline 24.2 & 50 & 15.9 & 9.7 & 1.0 & 0.7 & 30.4 & 37 & 54 & 0.24 & 3.1 \\
\hline
\end{tabular}

\subsubsection{Equipment and Instrumentation}

\section{a. Channel}

The channel or flume used in this study is an acrylic walled channel. This channel successively from upstream to downstream consists of 3 parts namely: Approach channel (approach flow) as long as $8 \mathrm{~m}$, curved section $180^{\circ}$ with axles radius, $R=1.25 \mathrm{~m}$ and downstream section (downstream) as long as 6 $\mathrm{m}$. To ensure the flow condition is a steady flow, then the flow is supplied from the head tank in the upstream section which is equipped with an overflow and a triangular overflow type measuring instrument. The detailed research sketch is presented in Figure 2.

\section{b. Bed Material}

The bed material used in this study is black sand, with a diameter of $0.8-1.2 \mathrm{~mm}$ and a mass density of $2.65 \mathrm{gr} / \mathrm{cm}^{3}$.

\section{c. Measuring Instrument}

The measuring instrument used in this study includes flow velocity measuring devices, discharge measuring instrument, water level/table gauge, bed topographic measuring instruments and time measuring instruments. The flow velocity measuring instrument used is the ADV type MicroADV 16 $\mathrm{MHz}$ with the ability to read instantaneous flow velocity up to 50 data per second. 


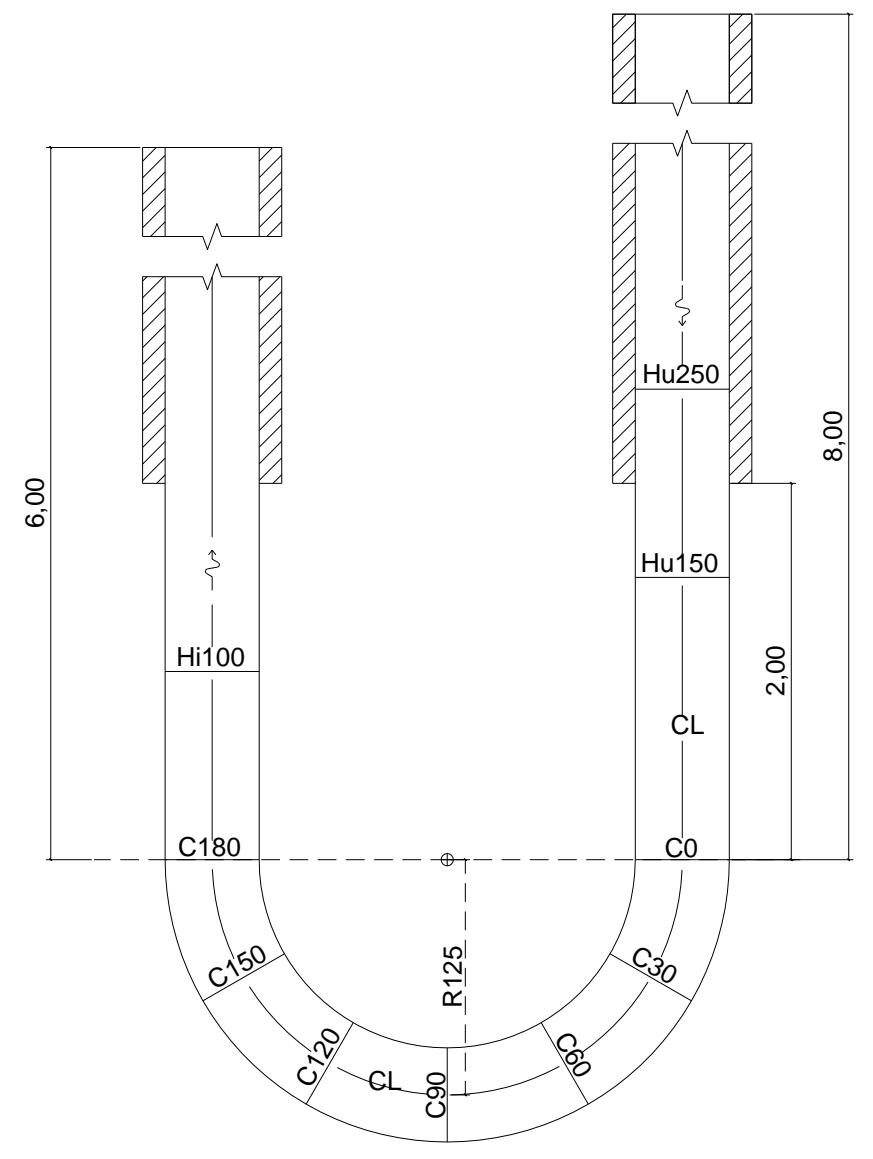

Figure 2. Sketch of curved open channel

The measurement of 3D velocity distribution in this study was carried out on seven curved angle section, i.e. at an angle of $0^{\circ}, 30^{\circ}, 60^{\circ}, 90^{\circ}, 120^{\circ}, 150^{\circ}$, and $180^{\circ}$, plus one measurement at approach flow. At each section carried out five measurements of vertical distribution, namely at position $\mathrm{R}=105$, $115,125,135$, and $145 \mathrm{~cm}$. The vertical distance between measurement points is $0.3 \mathrm{~cm}$ for data near the bed (inner region, at $z / h \leq 0,2$ ), and $1 \mathrm{~cm}$ for data in the outer region. Because of the shape and size of the probe ADV, there is a part of the flow that cannot be measured namely at a depth of about $5 \mathrm{~cm}$ below the water surface, and $5 \mathrm{~cm}$ width near the channel wall (see Figure 3)

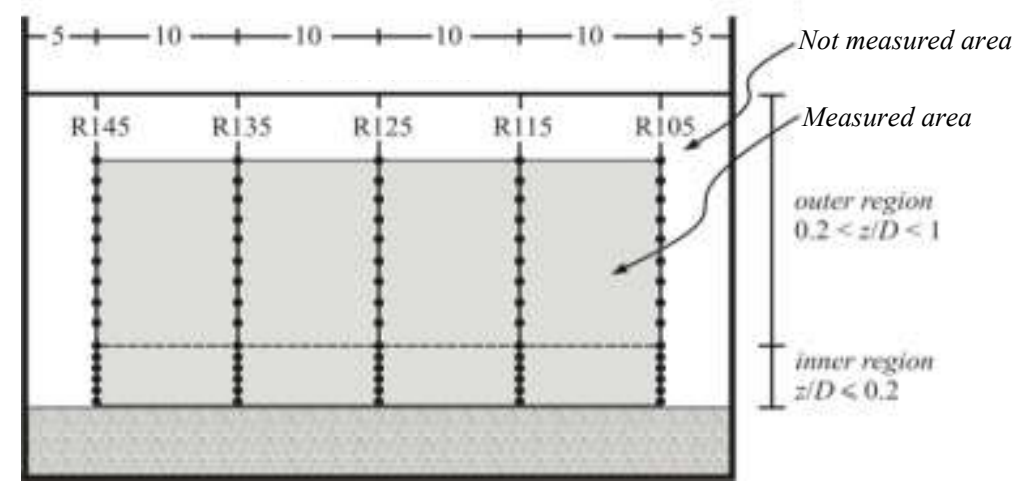

Figure 3. Velocity measurement point in each cross section 
Then the measurement data obtained is coded $\mathrm{C}$ and $\mathrm{R}$. For example, the data series with code C30R105 means that measurement is made in cross section $\mathrm{C}=30^{\circ}$ and at the radius position, $\mathrm{R}=105$ $\mathrm{cm}$. The following is shown the 3D flow velocity data collection method with ADV:

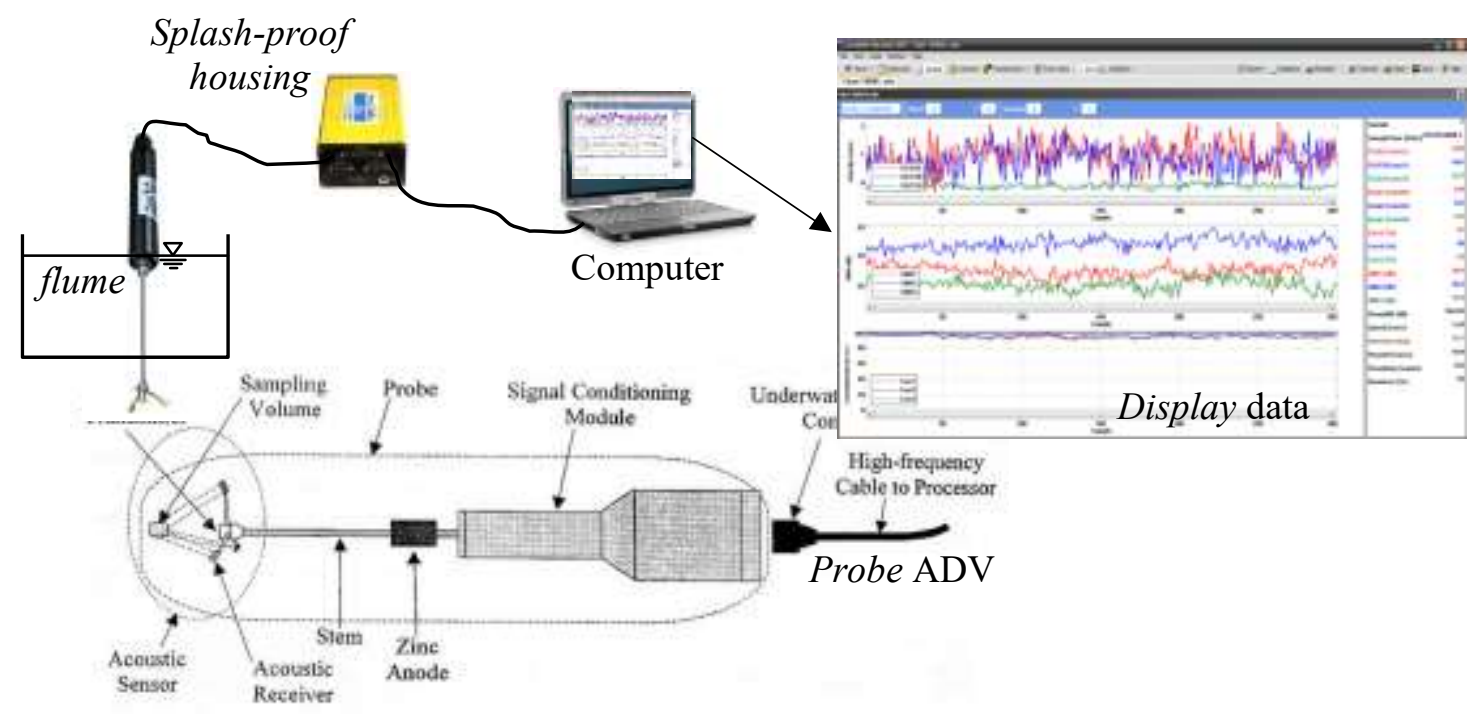

Figure 4. The data measurement method with ADV

Flow measurement using Micro ADV is also equipped with Sontek Horison ADV software so that measured data can be displayed in real time on a computer screen.

\section{Result and Discussion}

\subsection{Velocity Distribution}

In Figure 4 is given examples of the typical measurement results of velocity distributions with tangential, radial and vertical direction on the curved angle of $90^{\circ}$. For determining the shear velocity using the Clauser method, tangential directional velocity distribution data is used, especially in the inner region.
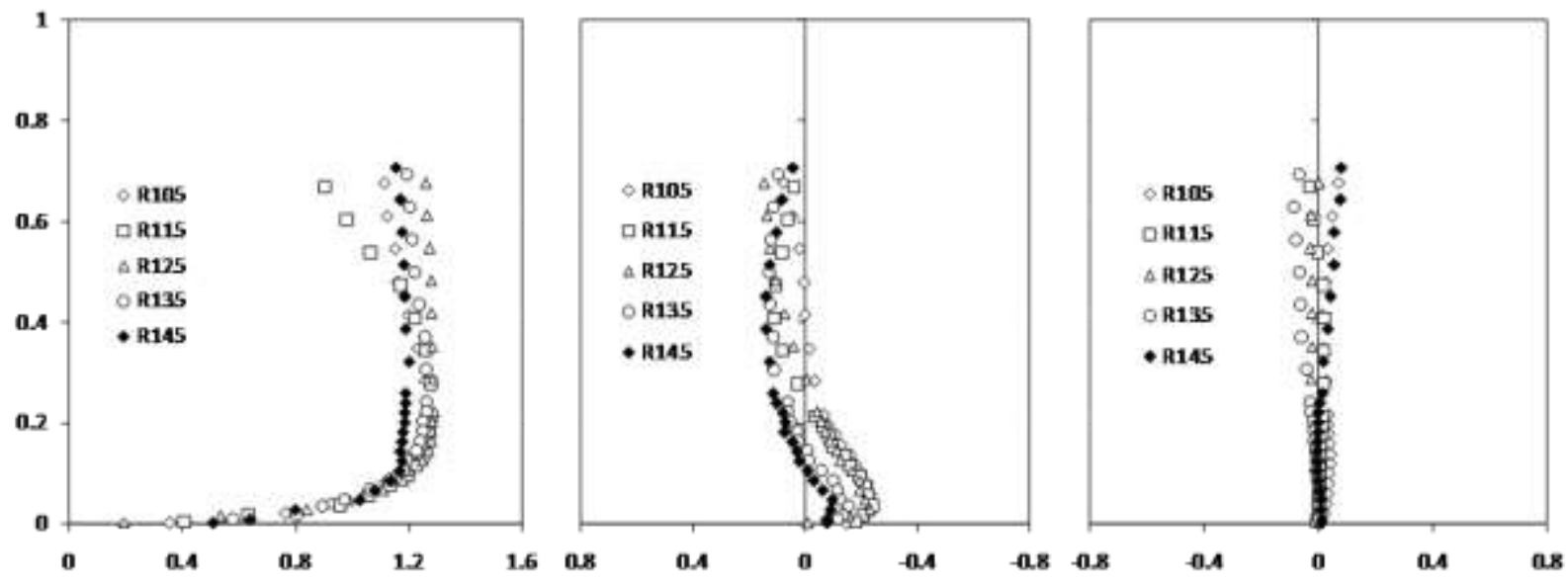

Figure 5. The velocity distribution in the direction of : (a) tangential, (b) radial and (c) vertical at the section of $90^{\circ}$ 
The tangential velocity distribution, for R115 data shows a shape that tends to close in the outer region $(z / h>0,2)$, while on the inner region $(z / h \leq 0,2)$, the shape of the velocity distribution showing trends similar to the flow in a straight channel (Figure 5).

For radial direction velocity, up to the depth of $z / h \approx 0.3$, radial velocity has a negative value, which means that the direction of the radial velocity toward the inside of the curve; while at $z / h>0.3$ the velocity has a positive value, which indicates that the direction of the radial velocity towards the outside of the curve. Whereas for the component of vertical direction velocity, the velocity value near the bed tends to be smaller compared to the velocity at a location far from the bed.

\subsection{Reynolds Shear Stress Distribution}

The following is shown a typical example of the measurement results of the tangential directional Reynolds shear stress distribution on several curved channel section. Seen in Figure 6, the shape of the Reynolds stress vertical distribution $-\overline{v_{z}^{\prime} v_{\theta}^{\prime}}$ and reaches zero values at the water surface (extrapolation results). Kironoto and Graf (1995) shows that the shape of the Reynolds stress distribution is linear for uniform flow, and nonlinear (concave or convex) for non-uniform flow, depending on whether the flow is accelerated or slowed.

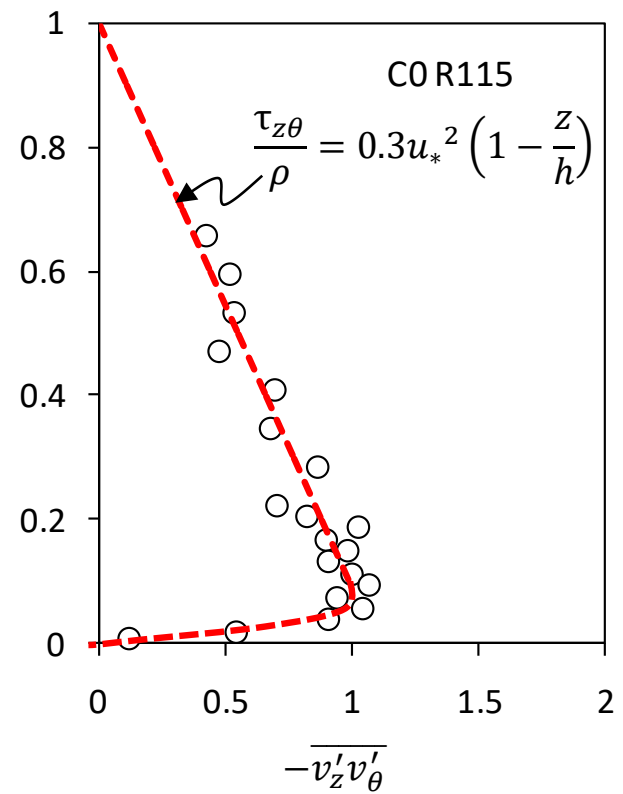

Figure 6. Reynolds stress distribution in curved inlet, $\mathrm{C} 0$

By using the regression method, the Reynolds stress vertical distribution equation is obtained $-\overline{v_{z}^{\prime} v_{\theta}^{\prime}}$ in the curved inlet follows the following equation:

$$
\frac{\tau_{z \theta}}{\rho}=0.3 u_{*}^{2}\left(1-\frac{z}{h}\right)
$$

As for areas that very close to the bed, theoretically the influence of flow viscosity is more dominant than velocity fluctuations. The flow velocity will also be close to zero on the bed surface $(z / h=0)$, as well as the value of velocity fluctuations. As a result the Reynolds stress distribution decreases and approaches zero as shown by 3 data near the bed. Thus it can be said that for areas that very close to the bed, shear stress is the total stress due to velocity fluctuations and flow viscosity. 
Furthermore, with the increase in curved angle, the vertical distribution of the Reynolds stress changes to non-linear even begin at $120^{\circ}$ curved angle in outer region $(z / h>0.2)$, the Reynolds voltage has negative value as shown in Figure 5.28 below. The influence of the centrifugal force on the flow in the curved channel causes the flow to accelerate, especially on the outside of the bend and deceleration on the inner side of the bend so that the shape of the Reynolds shear stress distribution is not linear.
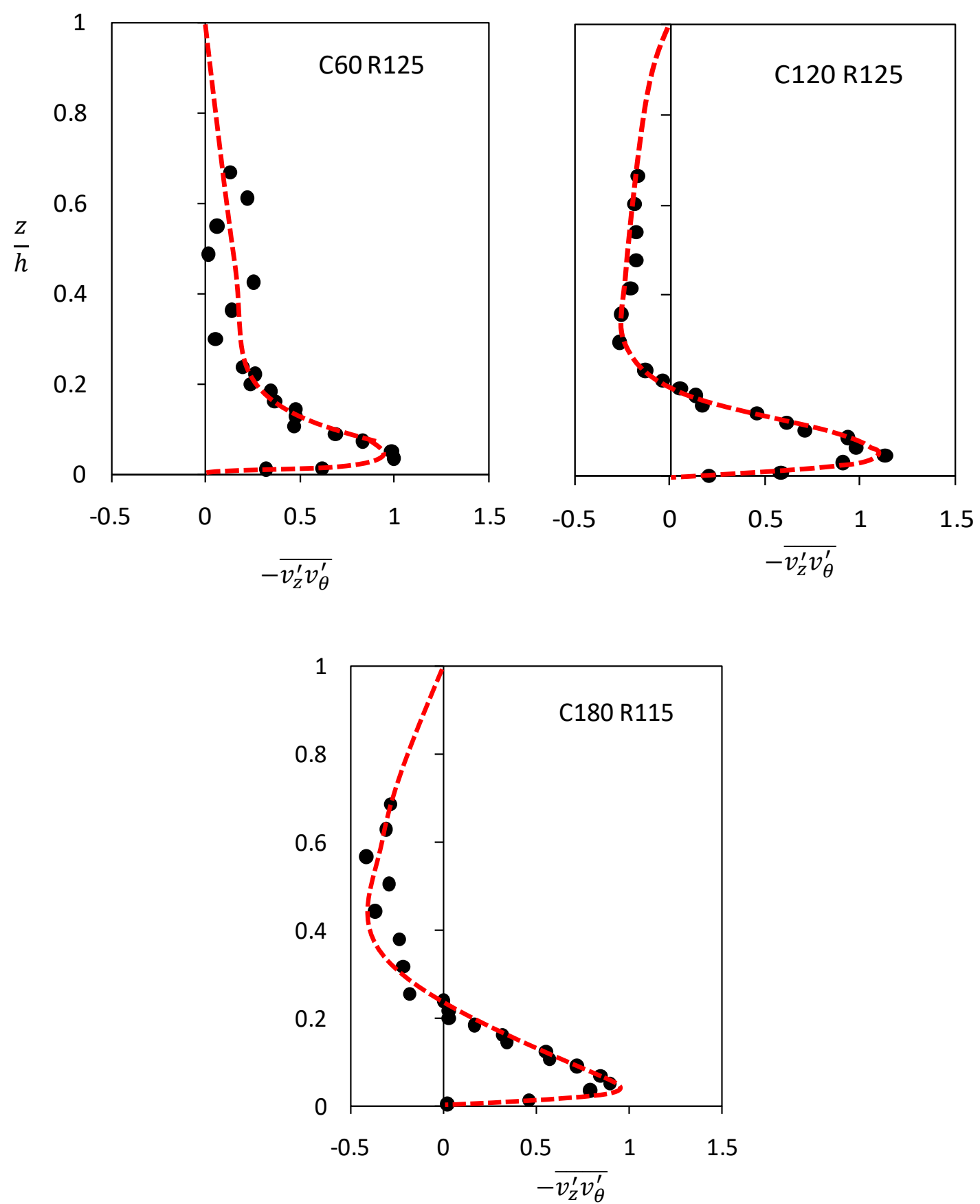

Figure 7. Reynolds shear stress distribution in curved channels for data:

(a). C60R125, (b) C120R125 and (c) C180R115 


\subsection{Bed-Shear Velocity}

In Figure 5 below is shown the example of $u *$ calculation with the Clauser method, for data C30R145. The plot of tangential velocity measurement data as the $y$ axis and $\ln \left(\mathrm{z} / \mathrm{k}_{\mathrm{s}}\right)$ as the $x$ axis, where $\mathrm{k}_{\mathrm{s}}$ is a bed roughness. With the linear regression method obtained a straight line with a gradient of $u * / \kappa$ and intersect the $y$-axis at coordinates $(0 ; B r . u *)$. With the same principle, can be calculated the value of the shear velocity, $u *$, for all data in the curved channel using the Clauser method. The results of the shear velocity calculation using the Clauser method in detailed presented in Table 2.

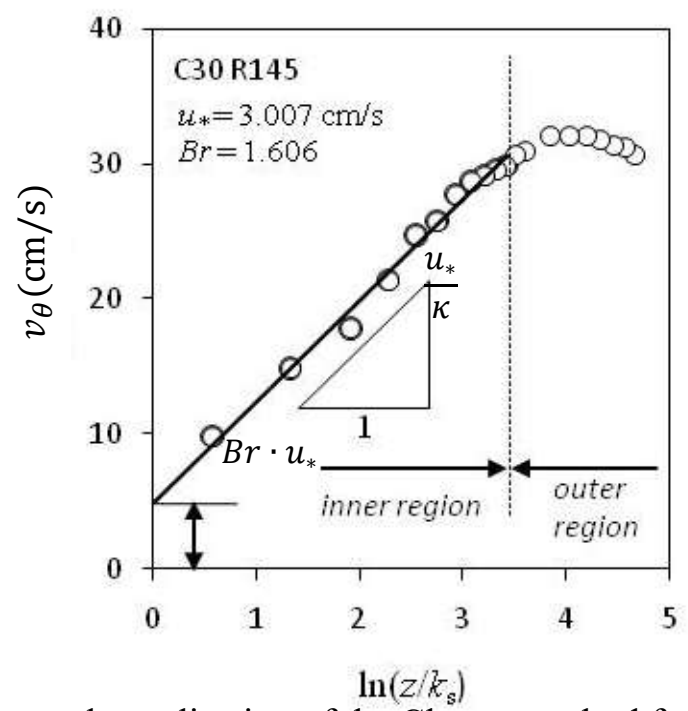

Figure 8. Example application of the Clauser method for data C30R145

Table 2. Value of bed-shear velocity, $u_{*}$ and constant $B r$ with Clauser method

\begin{tabular}{ccrrrrr}
\hline \multirow{2}{*}{ Code } & Parameter & \multicolumn{5}{c}{ Radius } \\
\cline { 3 - 7 } AF & $u_{*}$ & 1.711 & 1.653 & 1.566 & 1.575 & 1.815 \\
& $B r$ & 9.205 & 10.204 & 11.947 & 10.803 & 8.283 \\
\multirow{2}{*}{ C0 } & $u_{*}$ & 1.911 & 1.854 & 1.935 & 1.903 & 1.922 \\
& $B r$ & 7.078 & 8.279 & 7.896 & 7.640 & 8.960 \\
C30 & $u *$ & 1.942 & 2.133 & 2.212 & 2.261 & 2.474 \\
& $B r$ & 6.827 & 6.442 & 6.070 & 6.676 & 6.574 \\
C60 & $u *$ & 2.394 & 2.456 & 2.372 & 2.436 & 2.419 \\
& $B r$ & 5.284 & 6.043 & 6.554 & 6.079 & 5.748 \\
C90 & $u *$ & 2.277 & 2.382 & 2.317 & 2.368 & 2.314 \\
& $B r$ & 8.110 & 7.802 & 8.804 & 8.328 & 8.395 \\
C120 & $u *$ & 2.098 & 2.264 & 2.365 & 2.241 & 2.268 \\
& $B r$ & 9.603 & 8.027 & 8.325 & 8.216 & 8.763 \\
C150 & $u *$ & 2.166 & 2.492 & 2.588 & 2.402 & 2.624 \\
& $B r$ & 8.745 & 6.696 & 5.965 & 6.330 & 5.539 \\
C180 & $u *$ & 2.207 & 2.258 & 2.197 & 2.222 & 2.287 \\
& $B r$ & 9.919 & 8.793 & 8.045 & 6.181 & 6.096 \\
\hline
\end{tabular}


The following is an example of the data analysis of the Reynolds stress distribution on C120R135 data to obtain the value of the radial and transversal bed shear velocity. Furthermore, the total shear velocity value is the resultant of both.
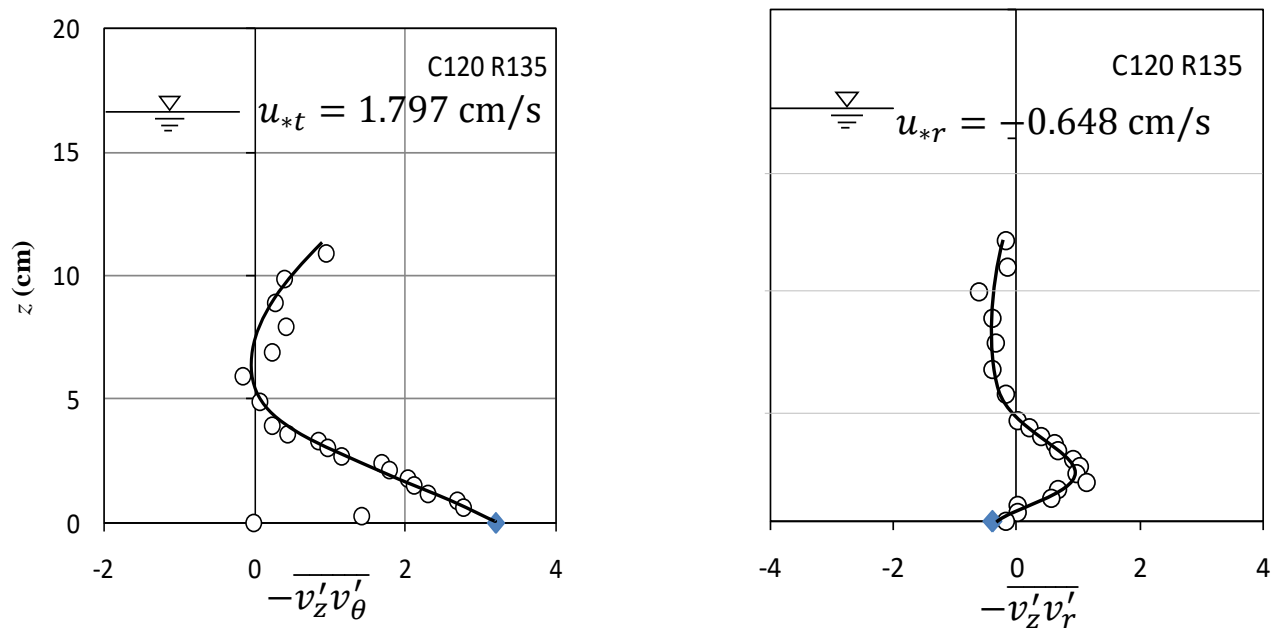

Figure 9. Example of the applications of the Reynolds stress distribution method for C120R135 data

In the same way, all of the Reynolds stress distribution data for other section can be calculated and the results in detailed presented in Table 3.

In Table 3, the number of tangential flow velocity data is also included -especially in inner regionwhich still follows logarithmic equations and is given a notation: $\mathrm{N}$. Based on the analysis of the data in Table 3, it is known that for the flow in the straight channel (sequence number 1 to 5), the Clauser method and the Reynolds stress distribution method produce relatively the same shear velocity where the average difference is $1.97 \%$.

Similarly in the curved inlet area $(\mathrm{C} 0)$, the average difference is still relatively small at $3.78 \%$. Whereas in the curved channel with the curve angle of $30^{\circ}$ until $180^{\circ}$ It can be seen that the two methods give different results where the Clauser method tends to produce a shear velocity value greater than the Reynolds stress distribution method with an average difference of $19.81 \%$.

Based on the bed shear velocity values obtained, it can be said that the Clauser method gives better results indicated by the value of the shear velocity in the curved section which is greater than the value of the bed shear velocity in the straight channel section.

From Table 3. It is also known that the shear velocity obtained by the Clauser method and the Reynolds stress distribution on the straight channel (approach flow) with HuCL code shows a relatively equal value with the average difference of $2.067 \%$. As well as in the curve inlet area, the average difference between the two methods is still acceptable namely $3.565 \%$. Further at curve angle of $\theta=30^{\circ}$ until $180^{\circ}$, Clauser method produces a greater shear velocity value than the Reynolds stress distribution method with an average difference of $2.693 \%$. Comparison of the results of the two methods is shown in Figure 10. 
Table 3. Bed-Shear Veocity according to Distribution of Reynolds Stress Method and Clauser Method

\begin{tabular}{|c|c|c|c|c|c|c|c|}
\hline \multirow{2}{*}{ No } & \multirow{2}{*}{ Code } & \multicolumn{3}{|c|}{ Dist. of Revnolds Stress Method } & \multicolumn{2}{|c|}{ Clauser Method } & \multirow{2}{*}{$\begin{array}{c}\text { Different } \\
\text { (\%) }\end{array}$} \\
\hline & & $u_{* t}$ & $u_{* r}$ & $u_{* R e}$ & $\mathrm{~N}$ & $u_{* C l}$ & \\
\hline 1 & $\mathrm{HuCL}+20$ & 1.710 & 0 & 1.710 & 8 & 1.711 & 0.021 \\
\hline 2 & $\mathrm{HuCL}+10$ & 1.658 & 0 & 1.658 & 8 & 1.653 & 0.299 \\
\hline 3 & $\mathrm{HuCL}$ & 1.523 & 0 & 1.523 & 8 & 1.566 & 2.828 \\
\hline 4 & HuCL-10 & 1.565 & 0 & 1.565 & 9 & 1.575 & 0.600 \\
\hline 5 & HuCL-20 & 1.703 & 0 & 1.703 & 10 & 1.815 & 6.589 \\
\hline 6 & C0R105 & 1.871 & -0.548 & 1.949 & 8 & 1.922 & 1.400 \\
\hline 7 & COR115 & 1.766 & -0.566 & 1.855 & 8 & 1.903 & 2.596 \\
\hline 8 & COR125 & 1.901 & -0.693 & 2.023 & 8 & 1.935 & 4.351 \\
\hline 9 & COR135 & 1.849 & -0.787 & 2.010 & 9 & 1.854 & 7.740 \\
\hline 10 & COR145 & 1.778 & -0.608 & 1.879 & 9 & 1.911 & 1.736 \\
\hline 11 & C30R105 & 1.957 & -0.620 & 2.053 & 8 & 2.474 & 20.498 \\
\hline 12 & C30R115 & 1.670 & -0.470 & 1.735 & 8 & 2.261 & 30.304 \\
\hline 13 & C30R125 & 1.817 & -0.580 & 1.907 & 8 & 2.212 & 15.974 \\
\hline 14 & C30R135 & 1.720 & -0.570 & 1.812 & 8 & 2.133 & 17.671 \\
\hline 15 & C30R145 & 1.616 & -0.550 & 1.707 & 8 & 1.942 & 13.810 \\
\hline 16 & C60R105 & 1.936 & -0.806 & 2.098 & 8 & 2.419 & 15.335 \\
\hline 17 & C60R115 & 1.764 & -0.728 & 1.908 & 8 & 2.436 & 27.679 \\
\hline 18 & C60R125 & 1.718 & -0.663 & 1.841 & 8 & 2.372 & 28.807 \\
\hline 19 & C60R135 & 1.822 & -0.742 & 1.967 & 9 & 2.456 & 24.821 \\
\hline 20 & C60R145 & 1.661 & -0.583 & 1.761 & 8 & 2.394 & 35.969 \\
\hline 21 & C90R105 & 1.825 & -0.866 & 2.020 & 9 & 2.314 & 14.554 \\
\hline 22 & C90R115 & 1.811 & -0.806 & 1.982 & 9 & 2.368 & 19.441 \\
\hline 23 & C90R125 & 1.808 & -0.800 & 1.977 & 9 & 2.317 & 17.156 \\
\hline 24 & C90R135 & 1.797 & -0.648 & 1.910 & 10 & 2.382 & 24.691 \\
\hline 25 & C90R145 & 1.453 & -0.548 & 1.552 & 9 & 2.277 & 46.675 \\
\hline 26 & C120R105 & 1.910 & -0.742 & 2.049 & 9 & 2.268 & 10.682 \\
\hline 27 & C120R115 & 1.903 & -0.872 & 2.093 & 8 & 2.241 & 7.071 \\
\hline 28 & C120R125 & 1.931 & -0.922 & 2.140 & 8 & 2.365 & 10.518 \\
\hline 29 & C120R135 & 1.797 & -0.632 & 1.905 & 9 & 2.264 & 18.809 \\
\hline 30 & C120R145 & 1.616 & -0.781 & 1.794 & 10 & 2.098 & 16.938 \\
\hline 31 & C150R105 & 1.977 & -0.787 & 2.128 & 9 & 2.624 & 23.277 \\
\hline 32 & C150R115 & 1.954 & -0.849 & 2.131 & 9 & 2.402 & 12.720 \\
\hline 33 & C150R125 & 1.865 & -0.889 & 2.066 & 9 & 2.588 & 25.251 \\
\hline 34 & C150R135 & 1.741 & -0.671 & 1.865 & 9 & 2.492 & 33.597 \\
\hline 35 & C150R145 & 1.565 & -0.640 & 1.691 & 9 & 2.166 & 28.052 \\
\hline 36 & C180R105 & 1.967 & -0.632 & 2.066 & 8 & 2.287 & 10.661 \\
\hline 37 & C180R115 & 1.755 & -0.707 & 1.892 & 8 & 2.222 & 17.460 \\
\hline 38 & C180R125 & 1.876 & -0.775 & 2.030 & 9 & 2.197 & 8.227 \\
\hline 39 & C180R135 & 1.800 & -0.548 & 1.881 & 9 & 2.258 & 20.001 \\
\hline 40 & C180R145 & 1.706 & -0.500 & 1.778 & 6 & 2.207 & 24.137 \\
\hline
\end{tabular}




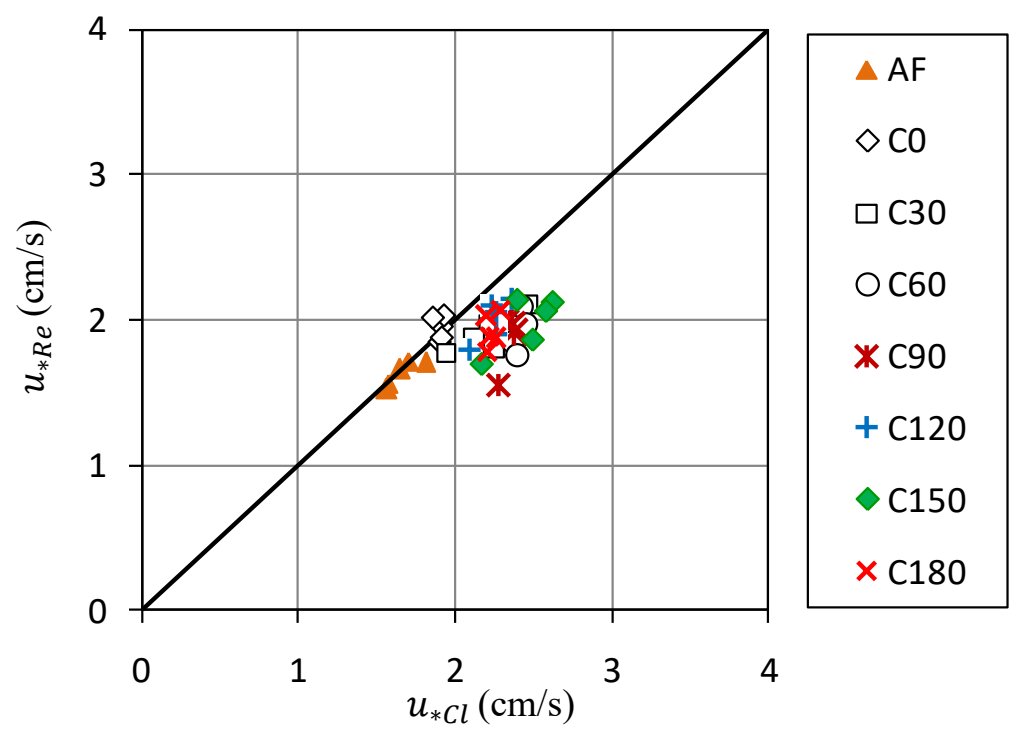

Figure 10. Comparison of the bed shear velocity values based on the Reynolds stress distribution and the Clauser method

\section{Conclusions}

Flow parameters in the form of shear velocities can be calculated using the Clauser method based on the velocity distribution data and the Reynolds shear stress distribution method. The results of calculations with both methods on a straight channel (approach flow) produce a bed-shear velocity value which relatively equal to the average difference of $1.97 \%$. Whereas in the curved channel, the results of the calculation of the two methods give an average difference of $19.81 \%$ where the Clauser method gives greater results compared to the Reynolds stress distribution method. In general, the Clauser method gives greater results compared to the Reynolds stress distribution method. Apart from the difference of up to $19.81 \%$, it can be said that in the flow in the curved channel, the bed-shear velocity can still be calculated using the Clauser method or based on the Reynolds shear stress distribution method.

\section{Acknowledgements}

Head of Hydraulic Laboratory University of Gadjah Mada, for the support of the Laboratory and the research tools (ADV and $180^{\circ}$ curved flume).

\section{References}

[1] B.A. Kironoto, B. Yulistiyanto, Istiarto, Sumiadi, A. Ariyanto, 2012. The Effect of Bed Shear Stress on Bed Topography Changes, Proceedings of Annual Scientific Meeting HATHI XXIX, Bandung.

[2] Bagherimiyab, F. and Lemmin, U. 2013. Shear Velocity Estimates in Rough-Bed Open-Channel Flow. Earth Surf. Process and Landforms 38, 1714-1724

[3] Graf, W.H., 1998. Fluvial Hydraulics, Published by John Wiley \& Son Ltd, West Sussex, UK.

[4] Jin, Y-C., Steffler, P.M. and Hicks, F.E., 1990. Roughness Effects on Flow and Shear Stress Near Outside Bank of Curved Channel, Journal of Hydraulic Engineering, 116(4), 563-577.

[5] Nikora VI, Smart GM. 1997. Turbulence characteristics of New Zealand gravel-bed rivers. Journal of Hydraulic Engineering ASCE 123: 764-773.

[6] Raupach MR. 1981. Conditional statistics of Reynolds shear stress in rough-wall and smoothwall turbulent boundary layers. Journal of Fluid Mechanics 108: 363-382.

[7] Song, T. and Graf, W.H., 1996. Velocity and Turbulence Distribution in Unsteady Open-Channel Flow, Journal of Hydraulic Engineering, 122(3), 141-154. 
[8] Song, T. and Chiew, Y.M., 2001. Turbulent Measurement in Non-uniform Open-Channel Flow Using Acoustic Doppler Velocimeter (ADV), Journal of Engineering Mechanics, 127(3), 219232.

[9] Sumiadi, Istiarto, B.A. Kironoto and D. Legono, 2011. Developing Laboratory Experiment on Flow in an Erodible Curved Channel, disajikan pada The 4th ASEAN Civil Engineering Conference, Yogyakarta.

[10] Sumiadi, B.A. Kironoto, D. Legono and Istiarto, 2011. Flow Characteristics in Eroded-bed Curved Channel, Proceedings of Civil Enginerring Post Graduate Conference (KNPTS), Bandung.

[11] Sumiadi, B.A. Kironoto, D. Legono and Istiarto, 2012. Distribution of Turbulence Intensity in Alluvial Channel Bend, Proceedings of Annual Scientific Meeting HATHI XXIX, Bandung. 